Sept.19th, Mr. C. C. Braine being the anæsthetist, I enucleated the prostate with some difficulty, the right lobe being very adherent to the surrounding tissues. There was scarcely any bleeding or shock. Section of the right lobe of the prostate (which weighed one and a quarter ounces) showed it to be carcinomatous. The patient made very favourable progress, passing urine naturally by Sept. 27th and the wound being practically closed by Sept. 30th, after which he sat up daily. On Oct. 15th whilst walking he felt faint, fell down, and rapidly expired from heart failure.

[Since this address was delivered on Oct. 20th, 1904, I have performed the operation in a further series of 34 cases, amongst whom there were two octogenarians. To complete the record to date I will give details of these two operations.]

CASE 155.-The patient, aged 83 years, was seen with Dr. J. C. Ferrier of South Norwood on Dec. 8th, 1904. Prostatic spmptoms had existed for five years; these had been much aggravated during the last two years. 'The patient had retention of urine 15 days previously and was entirely dependent on the catheter for ten days. There were much pain and difficulty in introducing the catheter and he was in great distress from cystitis, attempting to pass urine every few minutes. The prostate was enlarged, bilobed, tense, and moveable and was felt bimanually. 'The patient was stout; his general health was fair; the urine contained pus and albumin. On Dec. 10th he was conveyed to London by ambulance. After washing ont the bladder daily and preparing him for operation, on Dec. 20th, Dr. Ferrier assisting, opened the bladder suprapubically, removed a small urate stone weighing 39 grains, and then enucleated the prostate, weighing two and three quarter ounces, entire. The time occupied was five minutes. There was very little bleeding and no shock. No unfavourable symptoms supervened. Urine commenced to pass naturally on Jan. 9th and the wound was closed on the 12th. On the 16th the patient was walking about his room and on the 25th, when he left for home, he was in good health, passing and retaining his urine as well as he ever did. On Jan. 28th Dr. Ferrier wrote: "I am exceedingly pleased to see how well a man of his age has done after your operation."

CASE 160.-The patient, aged 80 years, was sent to me by Dr. A. M. Mitchell of Guildford on Jan. 11th, 1905. Prostatic symptoms had existed for four years. Retention of urine occurred one and three-quarter years ago and was relieved by catheter which had been regularly employed since then; he had been entirely dependent thereon for one year. He had had cystitis, hæmorrhages, intense pain in the penis during and after using the catheter, and the urine, which was alkaline, contained much pus and mucus. He had been in bed for seven weeks and was so feeble that he had to be conveyed to London by ambulance. The heart was very feeble with irregular and intermittent pulse. The prostate was bilaterally enlarged, soft, smooth, and moveable. Much pain and tenderness were felt during examination which were suspected to be due to the presence of vesical calculi. The patient's condition was very distressing, the catheter being introduced with much difficulty and pain. On Jan. 16th, Mr. C. C. Braine being the anæsthetist and Dr. Mitchell assisting, I removed four phosphatic calculi, weighing 185 grains, suprapubically and then enucleated the prostate entire without difficulty. The prostate projected into the bladder in the shape of an enormously hypertrophied cervix uteri with wide, irregular os. It weighed two and a half ounces. The time occupied was eight minutes, four of which were expended in removing the calculi. The operation was well borne and there was no shock. Progress has been most satisfactory, the patient soon regaining strength. Some urine was passed naturally on Jan. 24th and the wound was dry on Feb. 8th. He is sitting up daily in his room. He can pass and retain his urine (which is almost quite clear) as well as ever and will leave for the country in a few days.

Harley-street, $\mathrm{w}$

Scottish Poor-Law Medical Officers' AssoCIATION.-At a meeting of the executive council of this society held on Feb. 15th at Glasgow, Dr. William Cullen, vice-president, presented Mr. W. L. Muir with several handsome pieces of silver plate in appreciation of his indefatigable services as secretary of the association. The presentation was made by the unanimous wish of the association.

\section{ENELECTROLYSIS : AN IMPROVED METHOD OF OPERATING ON SUPERFLUOUS HAIRS.}

BY BALMANNO SQUIRE, M.B. LOND., SURGEON TO THE BRITISF HOSPITAL FOR DISEASES OF THE SKIK.

ThE extreme dislike evinced by most women to engaging in the habit of shaving when they are the subjects of superfluous hair, although this method is probably the best they can adopt for ridding, themselves of the disfigurement, and their almost invariable insistence on having the hair removed by electrolysis, renders any improvement in operating with the electrolytic needle a desideratum. The operation as hitherto practised is by no means ideal as to the results obtainable from it even in the hands of expert operators, and instances are by no means rare in which the effects of the operation have produced considerably more disfigurement than the original condition; the procedure has consequently in great measure fallen into discredit. As hitherto practised. the hair is taken as the guide for the direction in which the needle should be pushed with a view to its point reaching the root or papilla from which the hair grows and after the needle has been allowed to remain in situ for a period presumably long enough for the current to destroy the papilla, the hair thus operated on is seized by a pair of tweezers and very gentle traction is made on it; then if the hair comes out as if quite loose the hair papilla is considered, and with good reason, to be destroyed.

Quite recently, however, another mode of setting to work occurred to my mind-namely, to pull out the hair first and then to pass the needle into the hole left by the extraction of the hair. This difference, trivial as it seems, alters the whole character of the operation. It renders the destruction of skin that necessarily accompanies the destruction of the papilla very much less, and in consequence the scarring left after the operation is not very noticeable. It makes the operation a much more certain one-indeed, it converts it into an operation of precision. The upper lip, bitherto always by far the most difficult region to operate on, becomes as easy to deal with as the chin. One very important advantage of it is that it makes the procedure much more expeditious and another is that the pain caused by the introduction of the needle is notably less. My doubts as to this improvement before I had tried it were that in pulling out the hair first, often in itself a difficult thing to see, one at once loses one's only guide not only as to the point at which the needle should be inserted but also as to the direction in which it should be pushed; that, even if one could contrive to see the orifice of the hair follicle, one has lost in the plucked-out hair the clue to the precise direction of its slant. Then I feared that in passing the needle down the hair follicle the point would get caught in the wall of the follicle and thus diverted from the proper direction, and, lastly, I foresaw that the only test of success-namely, the hair yielding easily on traction with the tweezers-was rendered impossible. On trial, however, I found that not one of these objections was valid.

The drawbacks to the method hitherto in use are, on the contrary, by no means imaginary. The direction of the hair outside the skin is not a trustworthy indication of its direction in the substance of the skin. It shows the direction of the slant but not the degree of the slant, inasmuch as the majority of the bairs directly they $i$-sue from the skin become at once curved. I am aware that it has been claimed that a catheterisation by the needle of the hair-filled follicle is possible and that thus the hair-filled follicle will guide the sharply pointed needle to its right destination. A pretty considerable experience of the operation has convinced me that this is not so or at the most happens only in an extremely small percentage of the hairs operated on. As a rule the point of the needle, even when very carefully and slowly introduced, pierces the skin by the side of the follicle and arrives at its destination at a spot on one side of, and at a variable distance from, the papilla. The consequence is that an unnecessary destruction of the skin has to be produced in order that the destruction may radiate until it has reached the papilla; in short, that this has to take rlace visibly before the hair will come out under really gentle traction with the tweezers. Then, on pushing the reedlepoint into the skin, however slowly, so that its electrolytic 
action may, so far as possible, énable it to eat its way; still the mobile and elastic skin al aways gets imore or less pushed out of its proper place; for hairs always slant, and so the true direction of the hair gets lost. 'This is especially so on the extra mobile upper lip. In many instances the most practised operator finds that when he thinks he must have attained approximately the right direction the hair still sticks fast and will not come out on gentle traction, unless, indeed, a reorettable hole is at last burnt in the skin by the prolonged cauterising effect of the needle. The pushing of a needle, however fine,"'however" pointéd, 'and' however "polished, intô' the' 'skin is ' very' perceptibly resisted by 'the' skin unless; indeed, it be done with a jerk, which is inadmissible: for the purpose in question, and it pushes the skin before it even if the puncture be made perpendicularly to the surface, which is never possible in dealing with hairs on account of their pronnounced slant. This "is a great disadvantage of the method hitherto pursued.

As to the operation I now propose $I$ must premise that it is "quite possible to see the orifice of the hair follicle after the hair has been pulled out and that this being identified it becomes possible always to introduce the point of the needle into the hair follicle itself, a feat which is scarcely, if at all, possible to achieve unless the hair has first been pulled out. As to the direction in which the needle should be guided this can be known by carefully observing the exact direction of the hair before it is pulled out and even after this has been done considerable aid is afforded by observing the precise direction of slant and degree of slant of the neighbouring hairs. This being so it is easy to effect a true catheterisation of the hair follicle with the needle. In this manner the point of the needle touches the spot instead of arriving somewhere on one side of it. The needle if thus used enters the skin with the greatest ease, it does not in the least push the skin before it, and it does not displace the skin laterally. It has glided down a pre-existing tube which a No. 12 sewing needle fits quite easily. The introduction of the needle is much more expeditious, also it has to be left in the skin for a much shorter time because only a very short electrolytic action is required to destroy the papilla when the point of the needle is in actual contact with it. The whole process thus becomes much more expeditious. A much greater number of hairs can be operated on in a given time. The destruction of skin each time the needle is inserted is infinitely less and the scarring left is reduced to a minimum, not only by reason of the shorter action required of the current when the papilla has been reached but also by reason of the far more rapid introduction of the needle. It may, perhaps, be objected that one hereby loses one's test of success-the easy withdrawal with the tweezers of a loosened hair. One gains, however, in exchange a new and equally satisfying test. Here I must explain that I soon learnt that it is better to use the butt end (the eye end) of the needle than its pointed end. It slips down just as easily-indeed, more easily-because the point end is apt to stick and get caught in the walls of the follicle and is thus diverted from its aim. Now when one finds that the butt end of a needle enters the skin far more ea-ily than the point, as used in the ordinary way in the hitherto practised methods, one may be reasonably sure that it is passing down the follicle.

A word now as to the means of identifying the orifice of a hair follicle after the hair has been pulled out. The orifice is, of course, not boldly obvious; a little practice is naturally a great aid in discerning it. One is assisted too by taking the bearings of the orifice before the hair is pulled out; it may, for example, be in a line with the point of emergence of two other hairs and the three may be equidistant or what not. In any case, after pulling out the hair with the tweezers it is necessary to keep one's gaze fixed on the orifice until the needle has been inserted into it. The butt-end of the needle ought to be allowed to remain in the orifice for an instant so as to burn a minute funnel in it before the needle is allowed to glide in. For this instant the needle should be held perpendicularly to the surface and then slanted to approximately the right direction and the right slant. I say only approximately, for it is one of the great advantages of this method that, that being so, as soon as the needle is once engaged in the follicle it becomes guided in its further progress by the follicle itself. I have to admit that in performing this operation $I$ have the great advantage of being myopic to -8 dioptres but anyone who will put on spectacles of, say, +8 dioptres, will be in exactly the same position as myself for identifying the orifice of the hair follicle. 'The orifice under favourable conditions looks' like a vèry 'minute needle-prick. I would suggest as a distinctive name' for this method of operating. the 'word " enelectrolysis."

Weymouth-street, $\mathrm{W}$.

LACERATION OF THE ABDOMINAL WALL THE RES,ULT OF BEAR-BITE SIMULATING AN ABDOMINAL TUMOUR.

\section{BY Y. S. UMACHIGI, L.M.\&S.}

A MAN, aged 45 years, with a red fungoid pendulous. tumotir in the left hypochondriac region, was brought to the surgery from Castle-Rock on May 14th. The patient while returning home from his work in the jungles one evening was attacked by a wild bear. He received several nail-wounds on his chest and abdomen and a severe bite on the left side of his abdomen. He struggled hard with the bear, which at last ran away, leaving him disabled. After the injury a fleshy pendulous mass was seen protruding from the skin wound on his abdomen. The patient was weltering in blood on the spot and was helped to his hut by his companions. An attempt was there made by his fellow coolies to treat the wounds with some dark stuff. As he did not feel any relief from these applications and as the tumour began to increase in size they thought it fit to seek for better treatment and therefore took him to Castle-Rock exactly one week after he had received the injury. He was thence brought to Belgaum and into our surgery by a kind gentleman. On admission the patient looked quite exhausted and his condition appeared to be critical; his pulse was weak, his extremities were cold, and his face was pinched and drawn. His voice was low and he felt thirsty. There was no history of nausea or vomiting. He preferred the recumbent posture to sitting up, as the tension was relieved thereby. $\mathrm{He}$ said that he had felt a dragging pain throughout the week in the gastric region. On palpation the stomach was found to be distended and the spleen (which was malarial) was considerably enlarged; the liver was normal: The tumour presented beneath the costal arch of the left hypochondriac region. It had a fungoid appearance more or less pear-shaped with a notch at the fundus, the most dependent part, and had a pedunculated neck as it issued forth from the skin wound. It measured six inches long, seven inches around the fundus, and five inches around its peduncle. The thickness of the tumour was about two inches. The whole surface was looking very fleshy and was covered with stinking and thick pus. When the tumour was raised and the posterior surface exposed a central notch that extended nearly as far as half the depth of the tumour was noticed (which appeared to be the mark left by the teeth of the animal).

The tumour felt like an elastic mass. On gentle percussion a dull note could be elicited and the patient felt no pain A probe could be run around the peduncle of the tumour, between it and the border of the skin wound. The probe was, however, not forced deeper down for fear of entering the peritoneal cavity if it should be an abdominal tumour. The situation of the tumour just near the enlarged spleen, a marked notch on the border and another on the posterioc surface which very much resembled the hilum, and the elastic feel of the tumour led one to believe for some time that it might be an accessory spleen. The possibility of a portion of the transverse colon protruding was also not lost sight of. Hence, to make sure of its niture a small piece of it at the inner angle of the fundus was removed. This piece showed mostly fibrous structure with a rich supply of blood. Above all this, the patient having lived eight days after the receipt of the injury made me very doubtful of the tumour being abdominal unless localised peritonitis should have prevented it from infecting the general peritoneal cavity. Having made the usual preparations for the operation the tumour was removed; profuse hæmorrhage from several cut vessels was controlled by hæmostatic forceps and ligaturing. Trying to dissect it out at the peduncle, its firm attachment at the costal arch without any connexion with the abdominal cavity was noticed. The wound being dressed the patient was kept in bed and was directed to take perfect rest lest bleeding might set in again.

On examining the tumour after removal it had a film of 